\title{
3
}

\section{Action, Metaphor and Extensions in Kinship}

\section{Andrew Strathern and Pamela J. Stewart}

In this chapter we honour the fundamental and enduring contributions of Harold Scheffler to the study of kinship in human societies. Scheffler has vigorously pursued the topic of the primary reference of kin terms, and it is on this topic that the most controversy has tended to emerge. We recognise the force of Scheffler's arguments, and we seek to mediate between the different viewpoints on the fundamental issues at stake by considering the evidence further from contexts of action and from some aspects of linguistic theory. Scheffler also made important contributions to the study of descent and the question of cognatic descent as a category of analysis (e.g. Scheffler 1965, 2001), changing his mind about this arena of discussion in his 2001 book. We do not engage with this issue here, but it remains important, especially in the analysis of Pacific Island societies and their flexible systems of affiliation (see e.g. Strathern and Stewart 2004a on the Duna case from Papua New Guinea).

In our book Kinship in Action (Strathern and Stewart 2011) we argued that an important focus in kinship studies is found in the context of action as well as in linguistic classifications of kin types, foundational as these are for general frameworks of action. An action-based approach enables us to understand the pragmatic issues behind ways in which kin classifications are applied in practice. This argument is relevant for the long-standing debates in kinship studies regarding the 'meaning' of kinship terms; 
do they refer to primary kin types of a genealogical kind or do they refer to broad classifications? Clearly, in practice they can do both, depending on contexts of action. However, there is another way to enter the discussion. Language is intrinsically influenced by metaphorical applications of meanings, seen as 'extensions' from elementary structures that are tied to embodied experience. The 'extended mind' that evolutionary thinkers have identified as crucial for the development of human culture and language lends itself well to a context of sociality in which kin terms are applied both to close bodily relations and to wider sets of persons with whom cooperation is advantageous. 'Extensions', added to primary points of reference, are intrinsic to the whole process of human development. This viewpoint mediates between the opposing ideas of primary kin types versus kin classifications.

Kinship studies in anthropology, seen as being at the heart of the discipline in its early phases, have gone through a number of changes. Kinship terminologies were at first taken as proxy evidence for states of evolution of society. Theories of 'group marriage', for example, were broached as a means of apparently explaining classificatory terminologies. In these and other approaches one viewpoint tended to prevail: that a distinction between genealogical usages deriving from immediate links of reproduction (and marriage) and extended classificatory usages is to be found universally. In this viewpoint, the genealogical ties are implicitly taken as basic and self-explanatory and it is the classificatory usages that require further explanation. This explanation can then be found in terms of local logics of the equivalence of persons within genealogical grids or in terms of group or category membership and potentiality for marriage affiliations. While the concern for using kin-term structures as evidence for social evolution fell away, basic assumptions about the subject matter of kinship continued, and fed into a further phase of in-depth modelling of the putative logics of extension and equations between kin types. In the United States (US), this analytical method reached its climax in the work of the ethnoscientists who tended to equate 'culture' with linguistic classifications and developed extensionist kin-term analysis as a master art for revealing kinship structures. Among the many prominent exponents of this approach, the work of Floyd Lounsbury (e.g. Lounsbury 1964) clearly stood out, enabling a method of positing extension rules that could order the distribution of kin-term assignments over a set of genealogical positions, starting from basic genealogical foci. ('Genealogy', however, can itself also be an ambiguous term, referring either to ideas of biological 
procreation or to legal principles, or to both of these semantic domains.) Harold Scheffler and Floyd Lounsbury collaborated on a sophisticated analysis of the Siriono kinship system, exploring the strengths of this mode of analysis (Scheffler and Lounsbury 1971; see also Scheffler 1978 on Australian Kin Classification).

A strongly negative reaction against this method, and all other approaches that assumed a genealogical grid, came also from within the US with the work of David M. Schneider. Schneider's deconstructive strategy was to question the whole category of 'kinship' as a universal, genealogy-based grid of relations (Schneider 1984). In Schneider's view, the category was to be seen as ethnocentric, tied to English-language usages, and inapplicable as a general model. Schneider used the example of his work on Yap in Micronesia to question the genealogical basis of paternal filiation there, because the spirits of children were thought to come as a gift or form of bestowal from the ancestors (thagith), not from sexual procreation. A new child's name was accordingly given to it by male elders of the tabinau (local group) to which it was affiliated, acting in the place of the ancestors in this regard. Dogmas of this kind are common enough in societies with matrilineal descent (e.g. the famous but often misconstrued case of the Trobrianders of Papua New Guinea). The important thing is that they are dogmas, and that in practice and informally there is ample evidence of knowledge among the Trobrianders that sex and procreation are linked (see a discussion in Strathern and Stewart 2011: 36-38 and also 39-41 on the Yapese case with critiques of Schneider's argument). Schneider's stance, however, and his influence over others, gave rise to a school of cultural relativistic work on kinship that dissolved it as a category under sociality in general. Kinship studies as a separate domain of enquiry appeared to have suffered a serious blow.

More nuanced and thoughtful reconstructive approaches have since emerged. What we call kinship, in its social sense, can be composed of several elements, from basic significata, however these are formulated, to extended considerations of practice, embodiment, emplacement, consumption of food, political solidarity and the like. Especially food giving, care and identifications with locality have long been recognised as important for many New Guinea societies (see e.g. Strathern 1973; also Meigs 1984; Kahn 1986). What we call 'adoption' is another complicating factor in analysis, which can be resolved in various ways by stressing that kin terms refer to roles and statuses and in adoption the assumption of a parental role gives access to parental status. None of these 
complications necessarily validates or invalidates the general arguments about whether kinship is to be seen as based on genealogy or not. Rather, they obviate this argument by concentrating on practice as a domain in its own right. Among Melpa speakers of Mount Hagen in the Papua New Guinea Highlands, people will privilege either genealogical classifications or local solidarity, depending on circumstances. People also supplement kinship with friendship ties based on food sharing and the adoption of food names to make a more personal and special relationship of solidarity than a kin term alone can convey (see Strathern 1977). For the most part, then, a contemporary approach is to situate kinship relations within broader fields of sociality without, however, dissolving them entirely. The phenomenon of kin terms is culturally widespread, if not universal. It must obviously be rooted in embodied ('biological') facts that cannot be ignored. Kinship therefore survives as a living category of cross-cultural human behaviour and practice in spite of Schneider's deconstruction.

Warren Shapiro, editor of this volume, (pers. comm., n.d.) has pointed out to us, referring to one of his own writings (Shapiro 2009) that 'adoptive kinship is usually (always?) lexically marked, i.e. nonfocal'. The observation is true for the Melpa speakers of Papua New Guinea. A child taken over by someone else after the demise of its original parental figures is described as mbo nunggökli, 'nurtured'. Adoption was considered in some nuanced detail in various places in Strathern (1972), and also more recently in Strathern and Stewart (2011). Our point here is not to contest this issue, but to extend the argument into considerations of practice, while not denying the focal character of primary kin terms as Scheffler, and Shapiro following in the same vein, have done. We acknowledge here the arguments put forward by Shapiro in the present volume. Our own observations here about the importance of practice are also in effect fundamental to the topic of kinship at large.

The overall theoretical question nevertheless remains. Is there an essence of kinship that is culturally universal, and does it reside in the recognition of sexual and procreative relationships and the ties that derive from these as they are culturally defined? Our approach to this general issue is to deflect it further again, not just into the character of social practice but into the domain of linguistic practice. This can easily be justified by pointing out that the classic arguments have revolved around the interpretation of linguistic usages, specifically in relation to kin. The arguments have been all about semantics or meanings, and since the question of meaning is complex and disputed, it is little wonder that disagreements 
remain. Two further linguistic approaches are available. One is linguistic pragmatics. How do people use terms in practice? Clearly, they extend them in ways that suit their own pursuits of interests. Clearly, also, this cannot be done with total fluidity. Pragmatics require plausibility, and this means that some semantic principle has to be invoked to justify the usage. Gender, age, locality, marriage, or religion may all be called into play, leading to or resulting from ties of exchange. Indeed, for Papua New Guinea, exchange is certainly as fundamental a principle as any other, so it must be reckoned with in any consideration of the bases for sociality as well as the manipulation of these bases by aspiring leaders. Generally, then, contemporary ethnographic analyses of kinship as a topic have been guided by an exposition of cultural pragmatics.

Another resource from linguistic theory can be brought to bear on the problem in hand. This has to do with the meaning of the term meaning itself. There are endless arguments about this, implicating both philosophers and linguists. In general, these debates mirror the fundamental matters at stake in kinship theory. Do words have a core referential meaning which then can be extended by means of transfers or extensions, including to the realm that we call metaphor? This, again perhaps with an English language bias, might appear to be a common-sense statement. In fact, the whole idea of a metaphor, something carried over from one domain into another, tends to suggest this stance although the technical sense of the term 'extension' in kinship analysis is not identical with the term 'metaphor'. The one-to-one correspondence between words and things they ostensibly name in the world of observation and experience fails to take into account the much greater human capacity to build complex meanings through imagination and association. As one theorist, Robert Logan, put it, words can be 'strange attractors' of meanings (2007: 45-50). Also, as they are tools to explore human experience, words and the larger utterances in which they appear, as in poetry and song, acquire a power that goes far beyond their ability to name things. These observations suggest, in turn, that a tendency to accrete rich and complex meanings around at least certain terms in a given language is fundamental to the development of language itself as a consistent part of experience. This observation, then, can be applied to kinship terms. Such an observation in no way invalidates the notion of elementary meanings of kin terms, but it does suggest that because of their fundamental primary significance they lend themselves to productive extensions, and that their full range of meanings resides in such extensions as well as in an elementary referential 
or naming grid of references. Again, this does not amount to a denial of the theory of focal meanings for kin terms as classificatory devices. It does indicate that the extensions beyond such a focality are also socially important. This is not a trivial point, because it enables us to place debates about meaning in a broader context of action.

This chapter is not intended as a detailed exposition of the kin terms in a given societal area, such as among the Melpa speakers of Mount Hagen in Papua New Guinea. This kind of exposition was made in an earlier publication (Strathern 1980a). Nevertheless, we give here a few examples of how the analytical scheme we have outlined can be applied. We take the Melpa terms that are glossed under the rubric of 'father' (summarised in Strathern and Stewart 2011: 185). The basic reference term involved is tepam, while the address form is $t a$. In order to distinguish an 'immediate' sense of the term from other usages, the qualifier ingk, glossed as 'genuine', 'true', can be added, in a general contrast with tepam mburlukna, 'backside father', referring to same-generation collateral male kin on the father's side. Mburlukna thus operates as a modifier in conjunction with ingk. These two terms form an implicit semantic pair, mutually defined. So far, this clearly corresponds to the 'focal-meaning' theory of kin terms, as well as the theory of extensions. The extensions depend on the wider social structure of subclans and clans within which social relations modelled on the focal usages are extended. It is perhaps unnecessary to add that the extension of the term to lineal male collaterals in no way implies that the relationship of the propositus or hypothetical ego is the same with all of those classified in this way. Equally, however, the sheer fact of such a classification implies some basis of solidarity that is marked out, or made available, through the terminology itself. The classification lays out a determinate area of potentiality, demarcated from other arenas of the kin universe. From a sociocentric standpoint what is significant is that all those included in the class are tepamal, 'fathers' (in the plural form), and can be invoked or referred to as such, without any necessity for cited genealogical reckoning (although this may be known, if not to ego, then to others, and may be detailed in accordance with the situation). From an egocentric viewpoint, this class of tepamal also refers to a field of objective potentiality within which subjective affiliations can be sought or may be brought into play by the fathers/tepamal themselves. Obligations to help, support, or protect in warfare, disputes, or exchanges go with the classification. The extensions are cognitively 'real', and from this perspective they are important in the sociocentric context of clan relationships. The ingk classification, equally, 
is fundamental from the egocentric viewpoint. The overall logic has to be found in the combination of the egocentric and sociocentric domains, and it is this logic that provides the grounding for 'kinship in action' (the title of our book, Strathern and Stewart 2011).

Our observations here are founded on a detailed knowledge of social life and the place of kinship in it in the Melpa (Hagen) area, dating from 1964 to very recent times. They are not impressionistic or fleeting suggestions. When we write that kinship includes both egocentric and sociocentric aspects, we are also following in a tradition of writing that recognises these two domains of usage. However, we note that sociocentric usages among the Melpa are also founded on putative procreative relationships centring on ancestral figures.

Further classifications present other dimensions of complexity. Tepam as a reference term can also be applied to $\mathrm{MZH}$, normatively outside of the lineal clan relationship. How is this to be explained? The first example we gave depends on an equation in egocentric terms of F with FB; this further example rests on an equation between female siblings, such that $\mathrm{M}=\mathrm{MZ}$, and also $\mathrm{F}=\mathrm{MH}$, so we arrive at the proposition $\mathrm{MZH}=\mathrm{F}$. This is pure classification. In action terms MZH does not carry the same weight as F or FB; but again it marks out a field of potentiality, based as much on the presumed solidarity of sisters as on anything else. In essence, when we assess the social significance of these kinship classifications we have to go to the sphere of action in order to find the answers. This may be an obvious point, but it has to be borne in mind as a counter to analyses based purely on linguistic classifications.

Address terms present another level of cultural complexity. The term $t a$ is used reciprocally between father and son and between father and daughter. The address usages, signalling immediacy and intimacy of relationship, express the sameness of the relationship with the father among brothers and sisters, while the reference term is geared to differences in inheritance and succession associated with gender. In addition, however, the fact that the address terms are reciprocal points up another cultural value: the tendency to pair units. Ta indicates the shared relationship between father and child. As an extra marker the father may say kang ta or ambokla ta (boy-ta, girl-ta), and the child may say wuö ta (man-ta). What, then, is the focal meaning of $t a$ ? It seems to be the relationship F-Child rather than an elementary kin-type (such as $\mathrm{F}$ or $\mathrm{S}$ ). The reciprocal address term for M-Child is $m a$ (again, specifiable as ambokla ma or kang ma). Taking this 
into account reveals something important about the way the Melpa think of kin terms, which can be recognised only if we free ourselves from the assumption that the elementary units must always be markers belonging to a universal analytic language. Over and above this point there is the fact of divergence between address and reference contexts. The reference contexts do lend themselves to being parsed via single kintype categories. Two separate modes of classification thus operate within what we delimit as the kinship system. Moreover, as we have noted, the equations between kin types must not be taken as expressing complete identifications. Finally, here, 'father' terms are inflected also in terms of sibling order. Tepam komone is 'elder father', that is $\mathrm{FeB}$, and tepam akele is 'junior father', that is FyB. The overall outcome of these explorations into what we have deliberately picked out as very obvious aspects of the wider kin term system is that by this means it is evident both that focal meanings are present and important and that extensions are readily made and follow a grid that is stamped with wider structural relations. As well, there is the somewhat more radical point that Melpa address terms signalling shared intimacy or closures of relationship must be understood as elementary reciprocal pairs.

There is another way we can put all this, also derived from linguistic theory and its application to discussions of ritual action. Recent theories of ritual have concentrated on performativity and efficacy. Ritual actions that have performative effects have to be seen as comparable to what the philosopher J.L. Austin called 'illocutionary statements' (Austin 1962). Austin classified linguistic statements-and note here that we are discussing statements, not isolated lexemes or 'words'-as constative, illocutionary and perlocutionary. Constative statements were, for him, simple statements about the world, like referential namings. Illocutionary statements, by contrast, created situations in the world by their social performativity. It turns out that these kinds of statements tend to be important because of being constitutive of ritual actions. Statements in rituals, as well as nonverbal actions, create or affirm social realities and changes in these realities. Initiation rituals that confer a new status on people are iconic examples of this process. Perlocutionary statements are ones that have further consequences beyond, or separately from, illocutionary effects. They relate to possibly unintended but implicated results of statements. 
Perlocutionary effects are examples of the complex consequences of actions. In Austin's terms, the phrase 'You're fired' is an illocutionary statement, but the perlocutionary effects of such a statement may include a protest strike by a workers' union or the suicide of the person who is fired. Similarly a statement such as 'The argument of your paper is wrong' may result unintentionally in provoking enduring enmity or retaliation.

We can now apply a version of this tripartite classification of statements to the question of kinship terms. Some usages of terms may be simply constative, statements of a perceived or asserted naming of self-evident realities. These usages would correspond to what have been called 'focal' meanings. Other contexts of usage may have an illocutionary dimension. In other words, by naming someone as a kinsperson, they creatively make them so in the local context. As with all ritualised usages, this will work only if an authorisation of it is present in the overall context; but the statement itself is constitutive. For example, in certain field contexts, fieldworkers are defined as kin once they are taken in by a family. (This does not, of course, mean that they are confused with procreative kin.) An illocutionary moment occurs when a kin term is used and establishes this relationship. Kin terms in practice then operate across a constativeillocutionary continuum. Perlocutionary effects follow, because exchange relationships flow from such illocutionary moments. Interestingly, such moments are ritually displayed in the Mount Hagen society among local people themselves most strongly when two people decide to adopt food names, because a special ritual must be performed in order to make this relationship come into being, perhaps in addition to an existing kinship tie (see again Strathern 1977 for details of these remarkable practices of ritualised identity creation).

By bringing to bear these concepts from linguistic theory, thenpragmatics, theories of meaning, and the theory of illocutionary statements-we can situate arguments about kin terms in a way that is helpful and reformulates or adds to arguments about primary versus extended meanings. A virtue of this deployment of linguistic theory is that it resonates with a theory of kinship in action, the viewpoint we advocated in our book on kinship (Strathern and Stewart 2011). Kinship in action is not simply about meanings of terms, but about how people use these terms for vital purposes in practical lives. This approach both decentres kinship studies away from an exclusive concern with kin terms and recentres kinship as social action at the heart of ethnographic work, so that kinship is as kinship does, to adapt an expression ('handsome is as 
handsome does'). (For further instances of our examinations of issues in kinship analysis see Strathern 1972, 1973, 1980a, 1980b; Strathern and Stewart 2000a, 2000b, 2004b, 2006, 2010a, 2010b.)

Maurice Godelier's book on The Metamorphoses of Kinship is another sign of renewed interest in the topic of kinship studies (Godelier 2011). Godelier seeks to revisit all the classic sites of debate and to add some reflections on the state of kinship relations in developed, urbanised social contexts in the contemporary world. His work takes us away from the negative and deconstructive concerns of David Schneider's writings and back into discussion of major issues around the world, including the relationship between terminologies of kinship and social action. In a work of this scope, both the overall approach and the analysis of detailed cases are bound to be contested. Our own viewpoint enters into this domain from the side, as it were. We argue that to understand how kin terminologies work in practice, we must understand them in terms of general linguistic theories of meaning and also in terms of theories of social action. A combination of these viewpoints leads us to infer that kinship implies both a set of focal meanings and an important plasticity of usages in practice, modelled on the flexibility of social practice. Flexibility of the applications of meanings, in other words, goes hand in hand with the flexibility of practice, while such flexibility has to be modelled on a certain semantic grid that governs the extension of meanings. The argument between extensionism versus categories can therefore be reformulated so as to illuminate how social life operates. Instead of pitting these viewpoints against each other, we need to combine them into a single empirical and explanatory model of what kinship is all about, that is, linguistic and social practice.

Kinship studies, as we have noted at the outset, also began as a kind of handmaiden to discussions about social evolution. The approach we have advocated here resituates kinship in a kind of evolutionary context based on language. Evolutionary theorists such as Logan (2007: 241-51) have suggested the idea of the 'extended mind' as the means whereby shared language usages could have contributed to the emergence of human communities. Since this extension is an extension beyond each individual mind, to which each such mind contributes and from which it draws, it is clear that extension as such is an important cognitive basis for social life. (Our usage here is of course not the same as Scheffler's technically impeccable use of this term, but it does help to draw out the broad significance of such an idea.) It would seem highly appropriate, then, that one of the dimensions in which such an important extension could take 
place would be in the realm of kinship. In other words, the extensions of kinship terms were probably crucially instrumental in the evolution of the cognitive basis of solidarity in human communities-which is why the idiom of kinship continues to carry symbolic power in social rhetorics of unity and shared identity.

\section{References}

Austin, J.L. 1962. How to Do Things with Words. Oxford: Oxford University Press.

Babidge, Sally (ed.). 2010. Aboriginal Family and the State. London: Ashgate.

Comaroff, John L. (ed.). 1980. The Meaning of Marriage Payments. London: Academic Press.

Cook, Edwin A. and Denise O'Brien (eds). 1980. Blood and Semen: Kinship System of Highlands New Guinea. Ann Arbor: The University of Michigan Press.

Godelier, Maurice 2011. The Metamorphoses of Kinship, translated from the French original by Norah Scott. London: Verso.

Goodenough, Ward Hunt (ed.). 1964. Explorations in Cultural Anthropology: Essays in Honor of George Peter Murdock. New York: McGraw Hill.

Goody, Jack (ed.). 1973. The Character of Kinship. Cambridge: Cambridge University Press.

Kahn, Miriam 1986. Always Hungry, Never Greedy. Cambridge: Cambridge University Press.

Logan, Robert K. 2007. The Extended Mind: The Emergence of Language, the Human Mind, and Culture. Toronto: University of Toronto Press.

Lounsbury, Floyd G. 1964. 'A formal account of Crow- and Omaha-type kinship terminologies'. In Explorations in Cultural Anthropology: Essays in Honor of George Peter Murdock, edited by Ward Hunt Goodenough, 351-93. New York: McGraw Hill. 
McKnight, David. 2004. Going the Whiteman's Way. Kinship and Marriage among Australian Aborigines. London: Ashgate.

Meigs, Anna. 1984. Food, Sex, and Pollution: A New Guinea Religion. New Brunswick, NJ: Rutgers University Press.

Scheffler, Harold W. 1965. Choiseul Island Social Structure. Berkeley: University of California Press.

- 1978. Australian Kin Classification. Cambridge Studies in Social Anthropology No. 23. Cambridge: Cambridge University Press. doi.org/10.1017/CBO9780511557590

—. 2001. Filiation and Affliation. Boulder, CO: Westview Press.

Scheffler, Harold W. and Floyd G. Lounsbury. 1971. A Study in Structured Semantics: The Siriono Kinship System. Englewood Cliffs, NJ: Prentice Hall.

Schneider, David M. 1984. A Critique of the Study of Kinship. Ann Arbor: University of Michigan Press. doi.org/10.3998/mpub.7203

Shapiro, Warren 2009. 'A.L. Kroeber and the new kinship studies'. Anthropological Forum 19(1):1-20. doi.org/10.1080/00664670802 695418

Strathern, Andrew. 1972. One Father, One Blood: Descent and Group Structure among the Melpa People. Canberra: The Australian National University Press.

- 1973. 'Kinship, descent, and locality: Some New Guinea examples'. In The Character of Kinship, edited by Jack Goody, 21-34. Cambridge: Cambridge University Press.

- 1977. 'Melpa food-names as an expression of ideas on identity and substance'. Journal of the Polynesian Society 86(4):503-11.

- 1980a. 'Melpa kinship terms'. In Blood and Semen: Kinship System of Highlands New Guinea, edited by Edwin A. Cook and Denise O’Brien, 329-70. Ann Arbor: The University of Michigan Press.

- 1980b. 'The central and the contingent: Brideweath among the Melpa and the Wiru.' In The Meaning of Marriage Payments, edited by John L. Comaroff, 49-66. London: Academic Press. 
Strathern, Andrew and Pamela J. Stewart. 2000a. 'Kinship and commoditization: Historical transformations. Question de parenté. Special issue of L'Homme 154-55, 373-90.

—_. 2000b. 'Creating difference: A contemporary affiliation drama in the highlands of New Guinea'. The Journal of the Royal Anthropological Institute 6(1):1-15. doi.org/10.1111/1467-9655.t01-2-00001

- 2004a. Empowering the Past, Confronting the Future: The Duna of Papua New Guinea. New York: Palgrave-Macmillan. doi.org/10.1057/ 9781403982421

—_. 2004b. 'Preface: Anthropology and cultural history in Asia and the Indo-Pacific'. In Going the Whiteman's Way. Kinship and Marriage among Australian Aborigines, David McKnight, xv-xviii. London: Ashgate.

- 2006. 'Preface: Anthropology and cultural history in Asia and the Indo-Pacific.' In Family, Gender and Kinship in Australia, Allon J. Uhlmann, vii-ix. London: Ashgate.

_- 2010a. 'Kinship, ritual, cosmos'. Journal de la Societe des Oceanistes 130-131: 79-90. doi.org/10.4000/jso.6011

- 2010b. 'Anthropology and cultural history in Asia and the Indo-Pacific, series editors' preface: Kinship, process and history'. In Aboriginal Family and the State, edited by Sally Babidge, xi-xvi. London: Ashgate.

—_. 2011. Kinship in Action: Self and Group. Upper Saddle River, NJ: Prentice Hall.

Uhlmann, Allon J. 2006. Family, Gender and Kinship in Australia. London: Ashgate. 
This text is taken from Focality and Extension in Kinship: Essays in Memory of Harold W. Scheffler, edited by Warren Shapiro, published 2018 by ANU Press, The Australian National University, Canberra, Australia.

doi.org/10.22459/FEK.04.2018.03 